\title{
Distribution Static Compensator Using an Adaptive Observer Based Control Algorithm With Salp Swarm Optimization Algorithm
}

\author{
Jayadeep SRIKAKOLAPU, Sabha Raj ARYA, and Rakesh MAURYA
}

\begin{abstract}
In this work, an adaptive observer supported fundamental extractor is developed to estimate the fundamental components of the load current for a three phase distribution static compensator (DSTATCOM) under nonlinear load. Main variations in the proposed work are the fundamental drawing out from the distorted load current and estimation of PI controller gains. With this observer, salp swarm optimization algorithm (SSOA) is used for estimation of DC PI controller and AC PI controller gains. The estimated gains are used for $\mathrm{DC}$ bus voltage and $\mathrm{AC}$ terminal voltage error minimization respectively. This optimization algorithm commendably progresses the initial random solutions and converge to optimum. Pareto optimal solutions are approximated in SSOA with prodigious convergence and coverage. The SSOA can search unknown spaces and can deal with real world problems for solutions. The suggested control scheme with the optimized gain values has controlled the power quality issues like improving the total harmonic distortion (THD) of grid current and decreasing burden of reactive power on the grid caused due to a nonlinear load. The laboratory performance of the considered system with adaptive observer using d-SPACE-1104 has been provided for implementation work.
\end{abstract}

Index Terms-AC voltage controller, adaptive observer, fundamental extraction, harmonics, load balancing, salp swarm optimization.

\section{INTRODUCTION}

$\mathrm{T}$ HE modern loads are becoming more reactive in grid point of view. This creates a need in improvement of the power quality [1]. This produces the demand to supply reactive power to the grid to stabilize it and to full fill the consumer needs [2]. The non-linear loads connected to grid leads to power quality issues like total harmonic distortion (THD), distorted supply current and distorted voltage [3]. Current based distortions like current harmonics and reactive power demand, needs an active power line conditioner (APLC) to improve current based

Manuscript received March 9, 2020; revised June 30, 2020; accepted September 7, 2020. Date of publication March 30, 2021; date of current version March 1, 2021. This work was supported by Science and Engineering Research Board-NewDelhi Research Project under Extra Mural Research Funding Scheme, under Grant SB/S3/EECE/030/2016, Dated 17/08/2016.

All authors are with the Electrical Engineering Department, Sardar Vallabhbhai National Institute of Technology, Surat-395007, India (e-mail: sjaideep1729@gmail.com; sabharaj79@gmail.com; rmaurya@eed.svnit.ac.in).

Digital Object Identifier 10.24295/CPSSTPEA.2021.00005 power quality. These are well known as compensating custom power devices [4].

A conditioner which can operate in two operating modes: power factor correction mode and zero voltage regulation (ZVR) mode using a voltage source converter (VSC) is termed as distribution static compensator (DSTATCOM) [5]. This is made possible due to the development in power electronics and various fast and accurate signal processors used in controlling of these power converters [6]. The grid information acts as crucial part in different power system applications. Just like in a single phase system estimation of phase angle, amplitude of phase and its frequency is needed for real time govern of power system. By observing present grid scenario one can determine that there exist harmonic disturbances in grid parameters. These harmonic disturbances are due to grow usage of several nonlinear loads like induction motor drives, inverters and switch mode power supplies. In the last few years, for the guesstimates of grid parameters various number of operational approaches are proposed such as the fast Fourier transform (FFT)[7], Kalmen filtering [8], zero crossing detection (ZCD) [9], least square estimation [10], artificial neural networks [11], adaptive notch filter [12], and phase locked loop (PLL) [12]-[24] to name just few. PLL has received more concern than any other techniques mentioned above. PLL has simple structure and acceptable tracking performance. Orthogonal signal generation is vital part in PLL. In [12], a transfer delay block was used for the orthogonal signal generation this approximation of grid parameters might cause steady state errors. To overcome such steady state errors due to parameter estimation in [13], a second order generalized integrator based PLL was introduced. It is able to follow grid elements asymptotically during non-harmonic grid conditions. The authors in various PLLs [14]-[18] designed various PLLs to approximate fundamental grid components. Loop filters consisting in the design makes dynamic response slower. Few more PLLs like enhanced PLL [16], the instantaneous power PLL [19], the state variable feedback PLL [20], and quasi type PLL [21] were proposed to approximate the grid elements. According to the need steady state error has to be compromised with transient response using all these PLLs. For accurate estimation of grid parameters in these conditions with zero steady state estimate errors is needed. Although ZCD 
[4] method is simple in complexity but suffers with dynamic response often causing signal frights [22] provides a method which uses variable sampling frequency and provides good dynamic response. Because of the variable sampling frequency, it can cause steady state estimation error.

Other than the above mentioned grid parameter estimation methods the authors in [23] and [24] considered grid as dynamic system model and estimated the grid parameters using adaptive observer. However, the mentioned method shows steady state errors during harmonic grid conditions. The technique developed in [23] is on a single phase power system in which open loop detection method is used, this method depends on a frequency domain. But it suffers when input frequency diverges from its reference value. So a method which is not depending on PLL, complex filtering and quadrature singal generator (QSG), has been introduced in [24] using the theory of observer along with knowledge of adaptive estimation. Fundamental component estimation of the harmonic load current in the present work has been developed using an adaptive observer technique and zero steady state error approach for estimation of current parameters without harmonic disturbances. Dai, et al. [25] proposed an adaptive observer in which observer is used for monitoring voltage harmonics in single phase system. The mathematical analysis provides the extent of robustness of the adaptive observer for estimating the fundamental and other harmonic voltages. Due to estimation characteristics of fundamental components from non-ideal signal, it is effective in area of current based power quality problems. The complete algorithm is also needed error regulator as PI controllers. The regulation of PI gains is needed for regulating voltages using PI controllers to get necessary response of DSTATCOM. Optimization is a course of getting an optimized result; metaheuristic search helps in most cases produce high quality solutions [26]. Salp swarm optimization algorithm (SSOA) commendably progresses the initial random solutions and converge to optimum. Pareto optimal solutions are approximated in SSOA with prodigious convergence and coverage. SSOA can search unknown spaces and can deal with real world problems for solutions [27].

In this paper to estimate the fundamental current components of harmonic load current an adaptive observer with feedback approach has been introduced in three phase system. The ability to extract fundamental from the harmonic current during intermittency is improved due to its fast and precise action. This adaptive observer is robust to load harmonic current disturbances and even promises zero steady state error during load unbalance. The SSOA commendably progresses the initial random solutions and converge to optimum. The SSOA can solve challenging and computationally expensive design problems. The SSOA has been used for tuning PI gains as SSOA can search unknown spaces. The analysis provides detailed description and schematic of the adaptive observer along with operating principle. The recognized adaptive observer for the system has been supported by the simulation results and experimental verification on a laboratory setup.

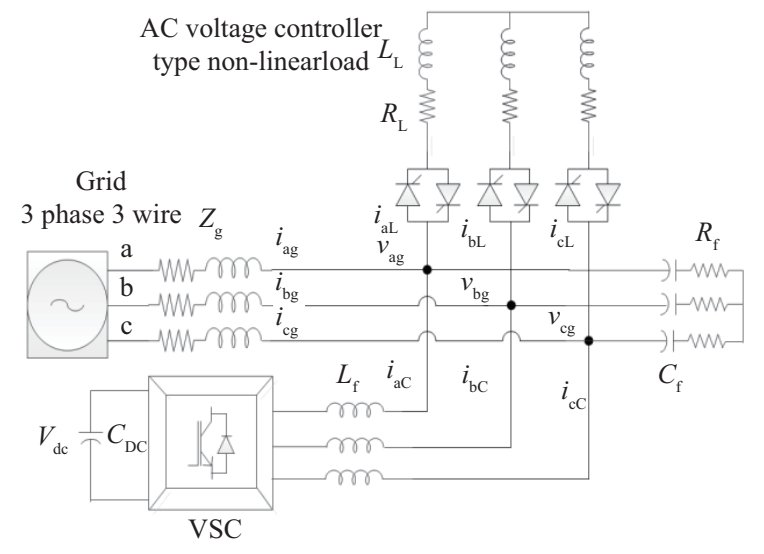

Fig. 1. Structure of DSTATCOM system and non-linear load.

\section{Structure of DSTATCOM System}

A converter with capacitor $\left(C_{\mathrm{dc}}\right)$ for maintaining the DC bus voltage $\left(V_{\mathrm{dc}}\right)$ is key component of DSTATCOM. General circuit diagram is shown in Fig. 1. AC voltage controller with resistance is considered as nonlinear load. Load currents $\left(i_{\mathrm{aL}}\right.$, $i_{\mathrm{bL}}$ and $\left.i_{\mathrm{cL}}\right)$ are with harmonics due to the nonlinear load. The grid currents $\left(i_{\mathrm{ag}}, i_{\mathrm{bg}}\right.$ and $\left.i_{\mathrm{cg}}\right)$ are made harmonic free using the compensating currents $\left(i_{\mathrm{ac}}, i_{\mathrm{bC}}\right.$, and $\left.i_{\mathrm{cC}}\right)$. The filter inductance $\left(L_{\mathrm{f}}\right)$ at line, passive ripple filter $\left(R_{\mathrm{f}}, C_{\mathrm{f}}\right)$ at point of common coupling (PCC) are supplementary components of the main circuit. Grid includes inherent impedance $\left(Z_{\mathrm{G}}\right)$. Signals needed for control algorithm proposed in Fig. 2 to control VSC are detected using Hall effect sensors.

\section{Control Algorithm}

The chosen adaptive observer for fundamental extraction for the system with DSTATCOM has been demonstrated in this section. The depiction of control scheme is portrayed in Fig. 2. DC bus voltage $\left(V_{\mathrm{dc}}\right)$, reference DC bus voltage $\left(V_{\mathrm{dc}}{ }^{*}\right)$, grid current $\left(I_{\mathrm{g}}\right)$, load current $\left(I_{\mathrm{L}}\right)$, PCC voltage and phase of grid voltage are the required signals for this purpose. The regulation of DC bus voltage is carried using DC PI controller in unity power factor (UPF) mode. The regulation of DC bus voltage and AC terminal voltage is carried using DC PI controller and AC PI controller respectively in ZVR mode. Gate pulses are generated for DSTATCOM control using the error signal obtained from estimated grid current and actual grid current.

\section{A. Design of the Recognized Adaptive Observer [25]}

Harmonic current consisting of fundamental component for phase " $\mathrm{A}$ " is defined as follows:

$$
i_{\mathrm{La}}=A_{\mathrm{m} 1} \sin (\omega t+\varphi)=A_{\mathrm{m} 1} \sin \psi_{1} .
$$

Considering $i_{\mathrm{La}}$ and its derivative the load current model is represented as, 


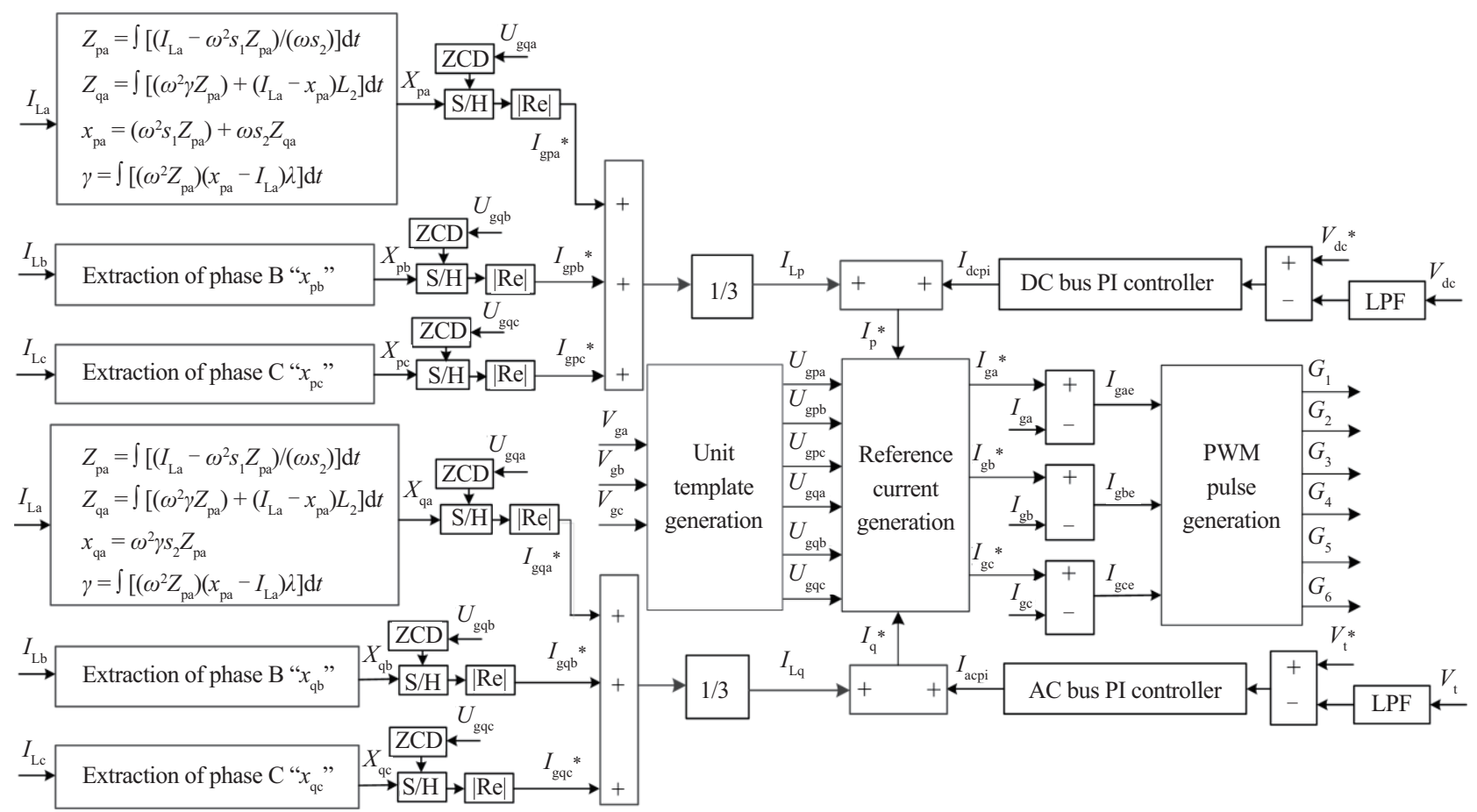

Fig. 2. Control algorithm of DSTATCOM using Adaptive Observer.

$$
\left\{\begin{array}{l}
\dot{X}=\bar{P} X \\
Y=\bar{R} X
\end{array}\right.
$$

Where $X=\left[\begin{array}{c}x_{\mathrm{pa}} \\ x_{\mathrm{qa}}\end{array}\right]=\left[\begin{array}{l}A_{\mathrm{m} 1} \sin \psi_{1} \\ A_{\mathrm{m} 1} \omega \cos \psi_{1}\end{array}\right], \bar{P}=\left[\begin{array}{cc}0 & 1 \\ -\omega_{\mathrm{n}}^{2} & 0\end{array}\right], \bar{R}=\left[\begin{array}{ll}1 & 0\end{array}\right]$.

$\omega_{\mathrm{n}}$ is the rated grid frequency and $\gamma=\left(\omega_{2}\right) /\left(\omega_{\mathrm{n}}{ }^{2}\right)$. The considered system is observable because

$$
\operatorname{rank}\left[\begin{array}{lll}
\bar{R} & R & \bar{P}
\end{array}\right]^{T}=2 .
$$

The estimate of fundamental current elements are formulated like an approximation for the considered linear dynamic structure in (2) with the unidentified parameters $\gamma$ related to the fundamental grid frequency based on the assessable signal $y=x_{\mathrm{pa}}=i_{\mathrm{La}}$. So to estimate the considered linear system with unknown parameters, designs of an adaptive observer for the dynamic structure for (2) is chosen. The adaptive observer is used to mine the fundamental quantities of the load current. Analysis for phase A is shown in equations below and similar method is followed for the remaining two phases. Phase quantity $x_{\mathrm{gpa}}$ and quadrature quantity $x_{\mathrm{gqa}}$ for phase A are shown in (5). The difference between $x_{\mathrm{gpa}}$ and actual load current is used for further calculations as shown below [25]:

$$
\begin{aligned}
&\left\{\begin{aligned}
Z_{\mathrm{pa}}= & \int\left[\left(I_{\mathrm{La}}-\omega^{2} s_{1} Z_{\mathrm{pa}}\right) /\left(\omega s_{2}\right)\right] \mathrm{d} t \\
Z_{\mathrm{qa}}= & \int\left[\left(\omega^{2} \gamma Z_{\mathrm{pa}}\right)+\left(I_{\mathrm{La}}-x_{\mathrm{pa}}\right) L_{2}\right] \mathrm{d} t
\end{aligned}\right. \\
&\left\{\begin{array}{l}
x_{\mathrm{pa}}=\omega^{2} s_{1} Z_{\mathrm{pa}}+\omega s_{2} Z_{\mathrm{pa}} . \\
x_{\mathrm{qa}}=\omega^{3} \gamma s_{2} Z_{\mathrm{pa}}
\end{array}\right.
\end{aligned}
$$

$$
\gamma=\int\left[\left(\omega^{2} Z_{\mathrm{pa}}\right)\left(x_{\mathrm{pa}}-I_{\mathrm{La}}\right) \lambda\right] \mathrm{d} t .
$$

Here $\mu>0$ and $\gamma>0$ are two design parameters which values are present to adjust the performance of identification.

The positive sequence component of load current $x_{\mathrm{pa}}$ moves at an angle to the reference in phase component $\left(U_{\mathrm{gqa}}\right)$. The drawing out of the fundamental part from the distorted current in phase "a" is done using ZCD with quadrature template $\left(U_{\text {gpa }}\right)$. The ZCD output triggers a sample and hold circuit whose input is $i_{\mathrm{L} 1}$. The magnitude of $i_{\mathrm{L} 1}$ is available at the output of sample hold circuit. Similarly $i_{\mathrm{gpb}}$ for phase "b" and $i_{\mathrm{gpc}}$ for phase "c" are calculated.

The load current active and reactive components are given by averaging all the active elements of the distorted currents as shown below (8) and (9):

$$
\begin{aligned}
& I_{\mathrm{Lp}}=\left(I_{\mathrm{gpa}}+I_{\mathrm{gpb}}+I_{\mathrm{gpc}}\right) / 3, \\
& I_{\mathrm{Lq}}=\left(I_{\mathrm{gqa}}+I_{\mathrm{gqb}}+I_{\mathrm{gqc}}\right) / 3 .
\end{aligned}
$$

\section{B. Unit Template Evaluation}

The sensed grid voltages $\left(V_{\mathrm{ag}}, V_{\mathrm{bg}}\right.$, and $\left.V_{\mathrm{cg}}\right)$ are used for evaluating terminal voltage and unit templates as shown below [28]:

$$
\begin{gathered}
V_{\mathrm{t}}=\sqrt{\frac{2\left(V_{\mathrm{ag}}^{2}+V_{\mathrm{bg}}^{2}+V_{\mathrm{cg}}^{2}\right)}{3},} \\
\left\{\begin{array}{l}
U_{\mathrm{gpa}}=V_{\mathrm{ag}} / V_{\mathrm{t}} \\
U_{\mathrm{gpb}}=V_{\mathrm{bg}} / V_{\mathrm{t}} . \\
U_{\mathrm{gpc}}=V_{\mathrm{cg}} / V_{\mathrm{t}}
\end{array}\right.
\end{gathered}
$$


Unit quadrature templates are given by the following equation set (12) as:

$$
\left\{\begin{array}{l}
U_{\mathrm{gqa}}=\left(-U_{\mathrm{gpb}}+U_{\mathrm{gpc}}\right) / \sqrt{3} \\
U_{\mathrm{gqb}}=\left(3 U_{\mathrm{gpa}}+U_{\mathrm{gph}}-U_{\mathrm{gpc}}\right) / 2 \sqrt{3} \\
U_{\mathrm{gqc}}=\left(-3 U_{\mathrm{gpa}}+U_{\mathrm{gpb}}-U_{\mathrm{gpc}}\right) / 2 \sqrt{3}
\end{array} .\right.
$$

\section{Switching Pulses Generation}

The DC bus voltage error obtained by subtracting actual and reference DC bus voltages is treated with a DC PI regulator to get DC loss component $\left(I_{\mathrm{dcpi}}\right)$. The terminal voltage error obtained by subtracting the actual and reference terminal voltages is treated with an AC PI controller to get the AC loss component $\left(I_{\text {acpi }}\right)$. The reference active and reactive components are given in following (13) and (14).

$$
\begin{aligned}
& I_{\mathrm{p}}^{*}(n)=I_{\mathrm{dcpi}}(n)+I_{\mathrm{Lp}}(n), \\
& I_{\mathrm{q}}^{*}(n)=I_{\text {acpi }}(n)+I_{\mathrm{L} \mathrm{q}}(n) .
\end{aligned}
$$

Reference grid currents are projected as shown below [11]:

$$
\begin{aligned}
& I_{\mathrm{ga}}^{*}(n)=U_{\mathrm{gpa}} \cdot I_{\mathrm{p}}^{*}+U_{\mathrm{gqa}} \cdot I_{\mathrm{q}}^{*} \\
& I_{\mathrm{gb}}^{*}(n)=U_{\mathrm{gpb}} \cdot I_{\mathrm{p}}^{*}+U_{\mathrm{gqp}} \cdot I_{\mathrm{q}}^{*} \\
& I_{\mathrm{gc}}^{*}(n)=U_{\mathrm{gpc}} \cdot I_{\mathrm{p}}^{*}+U_{\mathrm{gqc}} \cdot I_{\mathrm{q}}^{*}
\end{aligned}
$$

The error currents obtained by subtracting the $I_{\mathrm{g}}$ and $I_{\mathrm{g}}{ }^{*}$ are the modulating signals for generation of gate signals.

\section{Stability Study of Control Algorithm [29]}

It is important to notice that once the system quantities $\left(x_{\mathrm{pa}}\right.$, $x_{\mathrm{qa}}$ ) are without steady state error the unknown parameter $\gamma$ and the grid frequency $\omega$ can be approximated. An adaptive observer is developed to estimate the fundamental. A nonsingular transformation is considered i.e.,

$$
Z=\left[Z_{\mathrm{pa}} Z_{\mathrm{qa}}\right]^{T}=T X
$$

Where $T=\left[\begin{array}{cc}\omega_{\mathrm{n}} s_{1} & -s_{2} \\ \omega_{\mathrm{n}}^{2} \gamma s_{2} & \omega_{\mathrm{n}} s_{1}\end{array}\right] /\left(\omega_{\mathrm{n}}^{3} \gamma s_{1}^{2}+\omega_{\mathrm{n}}^{3} \gamma s_{2}^{2}\right), s_{1}>0$ and $s_{2}>0$, in terms of $\left(Z_{\mathrm{pa}}, Z_{\mathrm{qa}}\right)$ the considered system (2) can be stated as:

$$
\left\{\begin{array}{l}
\dot{Z}=P Z \\
Y=R Z
\end{array} .\right.
$$

Here $P=\overline{T P}^{-1}=\bar{P}, R=\bar{R} T^{-1}=\left[\begin{array}{ll}\omega_{\mathrm{n}}^{2} S_{1} & \omega_{\mathrm{n}} S_{2}\end{array}\right]$.

Now an observer is designed for the observable (19)

$$
\dot{Z}=\bar{P} \bar{Z}+L(R Z-Y) .
$$

To estimate the states $\left(Z_{\mathrm{pa}}, Z_{\mathrm{qa}}\right)$ where $Z$ is the approximation of $z$ and $\gamma$ is the approximation of $\gamma$,

$$
\bar{P}=\left[\begin{array}{cc}
0 & 1 \\
-\omega_{\mathrm{n}}^{2} & 0
\end{array}\right], L=\left[\begin{array}{cc}
\frac{-1}{\omega_{\mathrm{n}} S_{2}} & -L_{2}
\end{array}\right]^{T}
$$

For $L_{2}>0$. If the parameter $\gamma$ was known, the asymptotic estimation is achieved using the linear observer.

It is considered that the output error of the observer " $e$ " is as follows:

$$
\left\{\begin{array}{l}
e=(Y-R Z)=(R Z-R Z) \\
e=\dot{e}(R \dot{Z}-R \dot{Z})=(R P Z-R \dot{Z})
\end{array}\right.
$$

By substituting (19) into (21), we get

$$
\begin{gathered}
\dot{Z}=P Z+L(R Z-Y), \\
\dot{e}=P(e+R Z)-R[P Z+L(R Z-Y)], \\
\dot{e}=R(P-L R) R^{T} e-R(P-P) Z .
\end{gathered}
$$

Error of parameter estimation is written as:

$$
e_{\mathrm{u}}=\gamma-\gamma
$$

For the errors $e$ and $e_{\mathrm{u}}$ the Lypunov function has been considered as follows:

$$
\begin{gathered}
e^{T} e+\frac{e_{\mathrm{u}}^{2}}{\mu} ; \lambda>0=U\left(e, e_{\mathrm{u}}\right), \\
e^{T} \dot{e}+\dot{e}^{\cdot T} e+\frac{2 e_{\mathrm{u}}}{\mu} \dot{X}=\dot{U}\left(e, e_{\mathrm{u}}\right) .
\end{gathered}
$$

Substituting (10) in (12)

$$
\dot{U}\left(e, e_{\mathrm{u}}\right)=p_{1}+p_{2},
$$

where

$$
\left\{\begin{array}{l}
p_{1}=e^{T}\left\{\left[R(P-L R) R^{T}\right]^{T}+\left[R(P-L R) R^{T}\right]\right\} e \\
p_{2}=\frac{2 e_{\mathrm{u}}}{\mu} \dot{\gamma}-Z^{T}(P-P)^{T} R^{T} e-e^{T} R(P-P) Z
\end{array} .\right.
$$

Proper selection of " $K_{2}$ " and " $L_{2}$ " in $L$ i.e., $L=\left[\frac{-1}{\omega_{\mathrm{n}} S_{2}}-L_{2}\right]^{T}$ and $R_{\mathrm{e}}[\lambda(P-L R)]<0$, so that, part-1 of (13) would always less than zero except at origin [20]. So for the Lyapunov stability, part-2 of the (13) to be zero.

$$
\frac{2 e_{\mathrm{u}}}{\mu} \dot{\gamma}=Z^{T}(P-P)^{T} R^{T} e+e^{T} C(P-P) Z
$$

By the property of matrix transpose right hand side of (30) becomes, 


$$
\begin{aligned}
\frac{2 e_{\mathrm{u}}}{\mu} \dot{\gamma} & =2 Z^{T}(P-P)^{T} R^{T} e \\
& =2\left[\begin{array}{ll}
Z_{1} & Z_{2}
\end{array}\right] \times\left[\begin{array}{cc}
0 & -(\gamma-\gamma) \omega_{\mathrm{n}}^{2} \\
0 & 0
\end{array}\right] \times\left[\begin{array}{c}
\omega_{\mathrm{n}}^{2} \\
\omega_{\mathrm{n}}
\end{array}\right] \times e \\
& =-2 Z_{1} \omega_{\mathrm{n}}^{3} e_{\mathrm{u}} e \\
\dot{\hat{u}} & =-\mu \omega_{\mathrm{n}}^{3} e \times Z_{\mathrm{Pa}},
\end{aligned}
$$

where (32) is the updated law for the estimation parameter " $\hat{u}$ " for which $(28)$ is negative (i.e., $\left.\hat{U}\left(e, e_{\mathrm{u}}\right)<0\right)$. Thus shows its stableness according Lyapunov stability criteria.

\section{E. Estimating Controller Gains Using SSOA Algorithm [27]}

Optimal gains estimation using SSOA algorithm with an unconstrained optimization problem formulated with DC bus error minimization and $\mathrm{AC}$ terminal voltage error minimization is shown below. The termination criterion of this optimization problem is made with respect to voltage regulation which is of $0.28 \%$ and iterations which are of number 20 . The voltage errors in both UPF mode and ZVR mode form the minimizing objective functions $\left(C_{\mathrm{f}}\right)$ of algorithm.

The cost function $\left(C_{\mathrm{f}}\right)$ to be updated in PFC mode is as follows:

$$
C_{\mathrm{f}}=\int t e_{\mathrm{dc}}^{2}(t) \mathrm{d} t
$$

In ZVR mode, the cost function to be updated as:

$$
C_{\mathrm{f}}=0.5 \times\left[\int t e_{\mathrm{dc}}^{2}(t) \mathrm{d} t\right]+0.5 \times\left[\int t e_{\mathrm{ac}}^{2}(t) \mathrm{d} t\right],
$$

where $e_{\mathrm{dc}}$ and $e_{\mathrm{ac}}$ are voltage errors of DC and AC.

The chain of the salps is filled with followers and leader where the face of the chain is the leader and remaining salps follow the leader. The mathematical model of the salp swarm chains has been modeled considering leader and follower groups of salps. The designed variables number is " $n$ " in the given problem and the position of the salps is defined in an $n$ dimensional search space. The position of all salps is stored in a two dimensional " $x$ ". Assume that a food source " $F$ " in the define search space as the swarm's target. To update the new position of the leader the following equation is proposed.

$$
x_{j}^{1}= \begin{cases}F_{j}+r_{1}\left[\left(u b_{j}-l b_{j}\right) r_{2}+l b_{j}\right], & \text { if } r_{3} \geqslant 0 \\ F_{j}-r_{1}\left[\left(u b_{j}-l b_{j}\right) r_{2}+l b_{j}\right], & \text { if } r_{3}<0\end{cases}
$$

Where $x_{j}^{1}$ shows the position of the first salp (leader) in the $j^{\text {th }}$ dimension, $l b_{j}$ specifies the lower limit of $j^{\text {th }}$ dimension, $u b_{j}$ specifies the upper limit of the $j^{\text {th }}$ dimension, $r_{1}, r_{2}$, and $r_{3}$ are random numbers.

From the above expression it is evident that the leader updates its position according to the food source. In the balance of exploration and exploitation coefficient $r_{1}$ plays a key role.

$$
r_{1}=2 e^{-(4 p / P)^{2}}
$$

Where $p$ is the present or current iteration and $P$ is the maximum count of iterations.

Uniform generation of random variables $r_{2}$ and $r_{3}$ in the interval of $[0,1]$ is made. Moreover, they decide step size and direction of movement to positive infinity or negative infinity of the position in $j^{\text {th }}$ dimension. Follower positions are updated as shown below:

$$
x_{j}^{i}=\frac{1}{2} a t^{2}+v_{0} t
$$

Where $i \geqslant 2 x_{j}^{i}$ illustrates the position of $i^{\text {th }}$ follower salp in view of $j^{\text {th }}$ dimension, $t$ is time, $v_{0}$ is the initial speed, and $a=$ $v_{\text {final }} / v_{0}$ where $v=\left(x-x_{0}\right) / t$.

Because the time in optimization is iteration, the discrepancy between iterations is equal to 1 , and considering $v_{0}=0$, this equation can be written as follows:

$$
x_{j}^{i}=\frac{1}{2}\left(x_{j}^{i}+x_{j}^{i-1}\right)
$$

The proposed method is illustrated by means of a flow chart as shown in Fig. 3(a).

During DSTATCOM operation in UPF mode the course of the SSOA algorithm is shown in Fig. 4(a) and (b) against number of iterations. The cost function in UPF mode of operation is shown in Fig. 4(a) this has settled at 9395 in $8^{\text {th }}$ iteration. Fig. 4(b) shows DC PI gains $\left(K_{\mathrm{p}}\right.$ and $\left.K_{\mathrm{i}}\right)$ and their optimized value is seen as 2.5 and 0.17 in UPF mode. The cost function in ZVR mode of operation is illustrated in Fig. 4(c) this has settled at 6471 in $7^{\text {th }}$ iteration. Fig. 4(d) shows DC PI gains $\left(K_{\mathrm{p}}\right.$ and $\left.K_{\mathrm{i}}\right)$ and their optimized value is seen as 2.5 and 0.12 in ZVR mode. Fig. 4(e) shows AC PI gains $\left(K_{\mathrm{p}}\right.$ and $\left.K_{\mathrm{i}}\right)$ and their optimized value is seen as 2.13 and 0.23 in ZVR mode. These optimized values have maintained the DC bus voltage $\left(V_{\mathrm{dc}}\right)$ to $700 \mathrm{~V}$ and AC terminal voltage $\left(V_{\mathrm{m}}\right)$ to $339 \mathrm{~V}$.

DC bus PI controller performance for tuning gains through trial and error method (manual tuning) and gains calculation through optimization based method has been recorded during initial condition response in Fig. 3(b) and during dynamic condition in Fig. 3(c). On evaluating the response of DC bus PI controller with optimization and without optimization it is evident that maximum peak overshoot $\left(M_{\mathrm{p}}\right)$ is higher in the case of trial and error method (manual tuning) gains tuning during initial and dynamic conditions when compared with the optimized tuning gains. Whereas rise time $\left(t_{\mathrm{r}}\right)$ and settling time $\left(t_{\mathrm{s}}\right)$ are nearly same. The rise time $\left(t_{\mathrm{r}}\right)$ is calculated at $100 \%$ of the final value (i.e., 700) and settling time $\left(t_{\mathrm{s}}\right)$ is calculated based on 5\% tolerance band (i.e., 665-735). Moreover, maximum peak overshoot $\left(M_{\mathrm{p}}\right)$ is selected for under-damped system. The detail of time response parameter is given in Table I. Fig. 4(b) shows the DC bus voltage response during the dynamic condition. During the unbalance created in the system, the optimized gains are providing better response than the manual (Trial and error method) gains tuning. From Fig. 4 (b), (c) and Table I, it can be seen that the optimized gains show better 


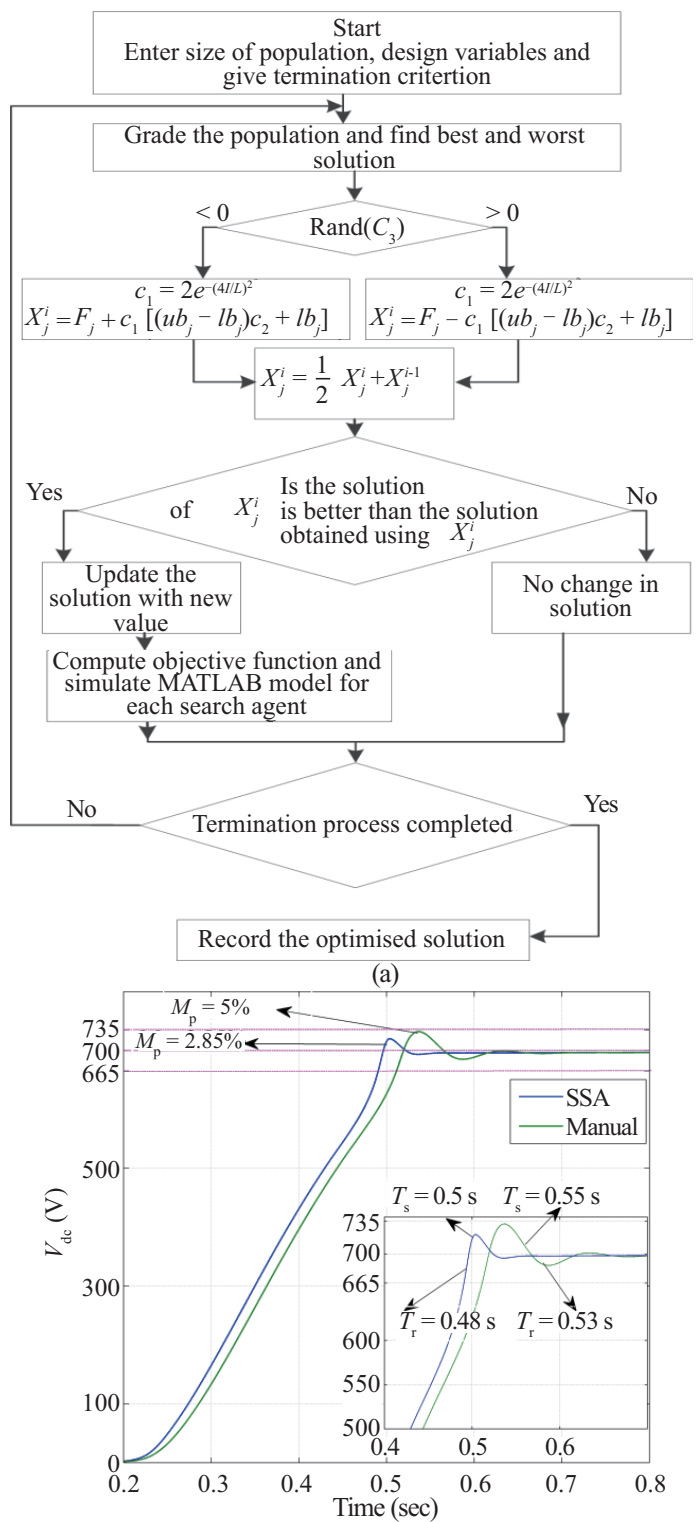

(b)

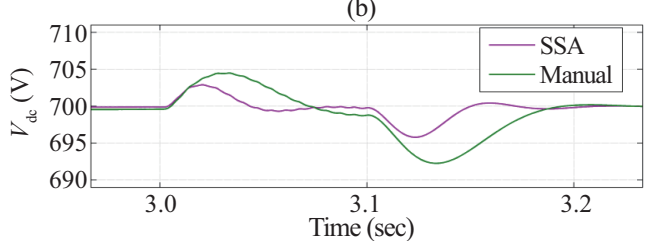

(c)

Fig. 3. (a) Flow chart of SSOA. (b) DC bus voltage analysis with out and with optimized PI gains. (c) Performance of the system DC bus voltage with out and with optimized PI gains in UPF mode for nonlinear load during dynamic condition.

response with less settling time and less peak over shoot.

\section{SimULATION IMPLEMENTATION}

The proposed adaptive observer based control algorithm has been verified using a simulated model of DSTATCOM developed in MATLAB. The simulation parameters with which the model has been built are provided in the appendix. With a sampling time of $10 \mu$ s the model is simulated for 3.5
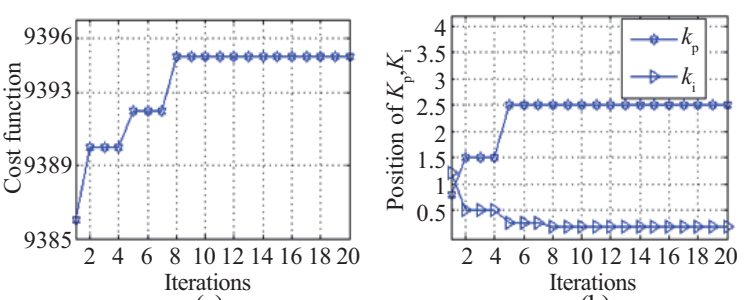

(a)
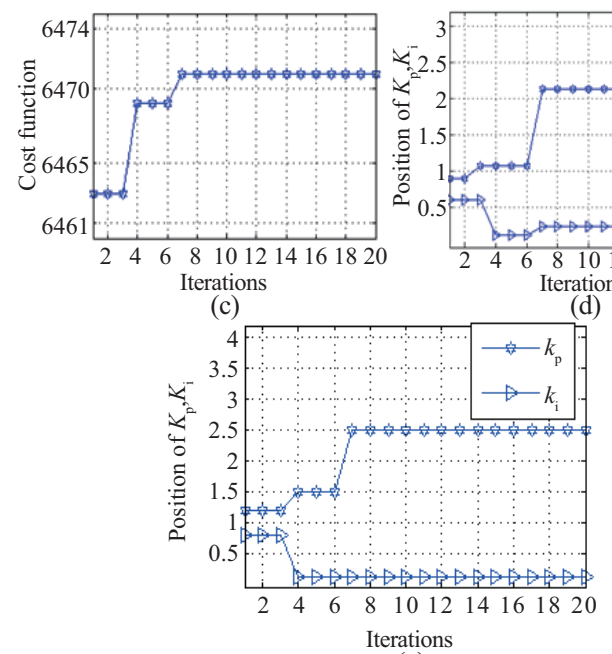

(e)
Fig. 4. Optimization analysis using SSOA algorithm. (a) Cost function versus iterations in UPF mode. (b) DC PI gains $K_{\mathrm{p}}$ and $K_{\mathrm{i}}$ versus Iterations in UPF mode. (c) Cost function versus iterations in ZVR mode. (d) DC PI gains $K_{\mathrm{p}}$ and $K_{\mathrm{i}}$ versus iterations in ZVR mode. (e) AC PI gains $K_{\mathrm{p}}$ and $K_{\mathrm{i}}$ versus iterations in ZVR mode.

TABLE I

Time Response Parameter of Tuning Method

\begin{tabular}{lcccc}
\hline \hline $\begin{array}{c}\text { Sr. } \\
\text { No. }\end{array}$ & Tuning method & $\begin{array}{c}\text { Rise time } \\
t_{\mathrm{r}} / \mathrm{sec}\end{array}$ & $\begin{array}{c}\text { Settling } \\
\text { time } \\
t_{\mathrm{s}} / \mathrm{sec}\end{array}$ & $\begin{array}{c}\text { Maximum peak } \\
\text { overshoot } \\
M_{\mathrm{p}} / \%\end{array}$ \\
\hline 1 & $\begin{array}{c}\text { Manual (trial } \\
\text { and error) tuning }\end{array}$ & 0.48 & 0.5 & 4 \\
2 & SSOA & 0.53 & 0.48 & 3 \\
\hline \hline
\end{tabular}

sec. Phase " $A$ " and phase " $C$ " are used for creating dynamics in the system. Unbalance in phase " $\mathrm{A}$ " is created from 3.0 sec to $3.1 \mathrm{sec}$ and unbalance in phase "C" is created from 3.1 sec to $3.2 \mathrm{sec}$. The PWM pulses are generated at a frequency of $5 \mathrm{kHz}$. The steady state and dynamic conditions for the considered adaptive observer based control are verified and results have been presented in the subsequent sections for UPF mode and ZVR mode.

\section{A. Variation of Internal Signals of Control Algorithm During Reference Grid Current Approximation}

Intermediate control signals of the control algorithm include load current $\left(i_{\mathrm{L}}\right)$, unit templates $\left(U_{\mathrm{gpa}}\right.$ and $\left.U_{\mathrm{gqa}}\right)$, load components $\left(I_{\mathrm{Lp}}\right.$ and $\left.I_{\mathrm{Lq}}\right)$ followed by reference grid current $\left(I_{\mathrm{g}}^{*}\right)$ and actual grid current $\left(I_{\mathrm{g}}\right)$. The performance of the internal parameters 


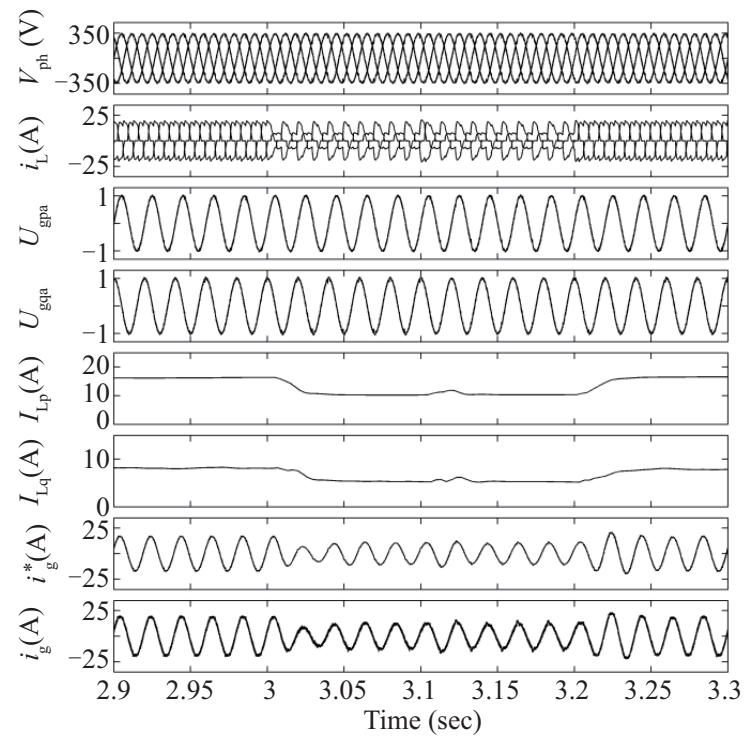

Fig. 5. Internal signals of proposed adaptive observer in UPF mode and ZVR mode.

for the proposed control algorithm has been illustrated in Fig. 5. The internal signals are shown from subplots (2-7) in Fig. 5.The new method of approach using adaptive observer properly estimates the fundamental components of load current components. This has been achieved by filtering out the disturbance caused by the load using considered adaptive observer. The wave forms of fundamental load current are almost sinusoidal. The reactive load current $\left(I_{\mathrm{LQ}}\right)$ is shown in subplot 6 , indicates the inductive type of load. The active part of load current $\left(I_{\mathrm{LP}}\right)$ is shown in subplot 5 , indicates the stable and controlled operation of the given control algorithm. By observing subplots 7 and 8 it has been concluded that the actual grid current is always tracking the reference grid current along with variation in fundamental during load dynamics.

\section{B. Performance Analysis of the Main Signals During Load Dynamics in UPF Mode and ZVR Mode}

The control algorithm of DSTATCOM using proposed adaptive observer has been analyzed with system parameters grid phase voltage $\left(V_{\mathrm{ph}}\right)$, grid current $\left(I_{\mathrm{g}}\right)$, load current $\left(I_{\mathrm{L}}\right)$, DSTATCOM compensating currents $\left(I_{\mathrm{aC}}, I_{\mathrm{bC}}, I_{\mathrm{cC}}\right)$, DC bus voltage $\left(V_{\mathrm{dc}}\right)$, terminal voltage $\left(V_{\mathrm{m}}\right)$. A nonlinear load (AC voltage controller) with load imbalance at $3.0 \mathrm{sec}$ to $3.2 \mathrm{sec}$ is used. The response of the system in these conditions and with these parameters has been analyzed in two different modes namely UPF mode and ZVR mode. The adaptive observer based control algorithm for the modeled DSTATCOM response is shown from $2.9 \mathrm{sec}$ to 3.3 sec. The system performance with proposed adaptive observer in UPF mode is illustrated in Fig. 6 dynamically. Grid currents $\left(i_{\mathrm{ag}}, i_{\mathrm{bg}}, i_{\mathrm{cg}}\right)$ are shown in Fig. 6 at sub graph 3 to sub graph 5 . The balanced grid currents are evident for the proper working of adaptive observer during load dynamics. The compensating currents of VSC are shown in Fig. 6 at sub graph 6 to sub graph 8 are evident for grid current reactive power compensation. The DC bus voltage profile is shown in Fig. 6 at sub graph 9. The effective

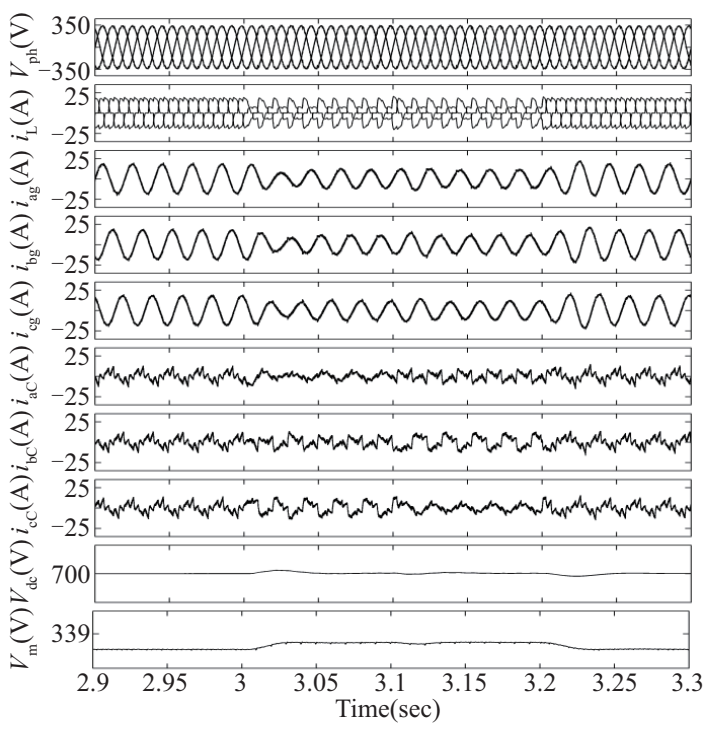

Fig. 6. Dynamic analysis in UPF mode for the system with nonlinear load.

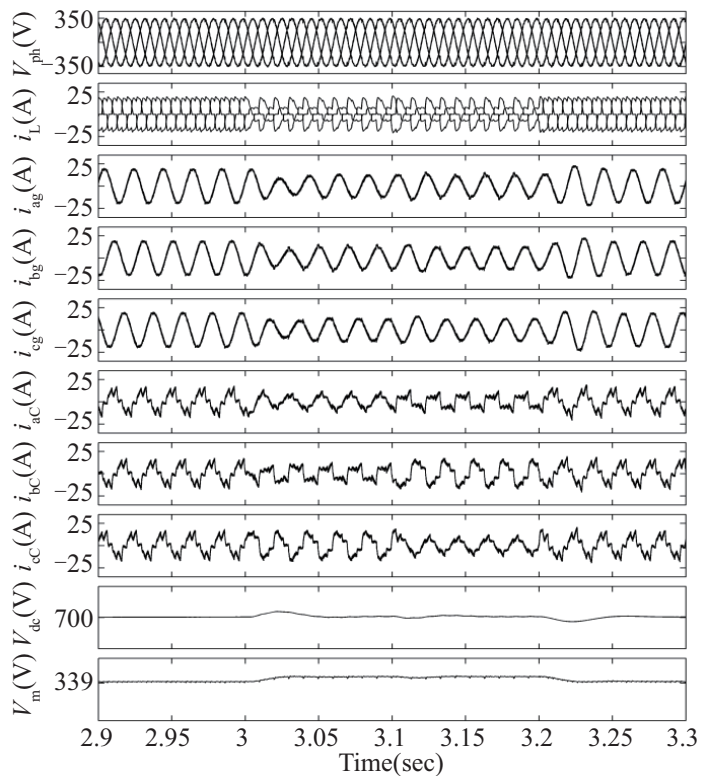

Fig. 7. Dynamic analysis in ZVR mode for the system with nonlinear load.

regulation of DC PI controller is evident from the DC bus voltage profile. By witnessing grid voltage $\left(V_{\mathrm{ph}}\right)$ and grid current $\left(i_{\mathrm{ag}}\right)$, it has been decided that both are in phase this shows the appropriate UPF mode during load dynamics. Restoration of DC bus voltage to its original value is made in two fundamental cycles during load dynamics.

The dynamic performance of the system in ZVR mode is illustrated as shown in Fig. 7. The justification of the ZVR mode can be made by observing the terminal voltage amplitude $\left(V_{\mathrm{m}}\right)$. Restoration of DC bus voltage and AC terminal voltage to their intended values is made in two fundamental cycles. By observing grid voltage $\left(V_{\mathrm{ph}}\right)$ and grid current $\left(i_{\mathrm{ag}}\right)$, it can be concluded that grid current $\left(i_{\mathrm{ag}}\right)$ is leading from grid voltage $\left(V_{\mathrm{ag}}\right)$ which demonstrates the suitable ZVR mode during load dynamics. The harmonic analysis is provided in Table II for 
TABLE II

Level of Harmonic Response of Parameters

\begin{tabular}{lccccc}
\hline \hline \multirow{2}{*}{ Parameter } & \multicolumn{4}{c}{ Operating mode } \\
\cline { 2 - 3 } & \multicolumn{2}{c}{ UPF mode } & & ZVR mode \\
\cline { 2 - 3 } \cline { 5 - 6 } & Magnitude & THD $\%$ & & Magnitude & THD $\%$ \\
\hline Grid voltage $\left(V_{\mathrm{ag}}\right)$ & 334.8 & 3.23 & & 338.6 & 2.88 \\
Grid current $\left(I_{\mathrm{ag}}\right)$ & 17.98 & 4.96 & & 18.89 & 4.75 \\
Load current $\left(I_{\mathrm{aL}}\right)$ & 18.87 & 21.81 & & 19.12 & 21.74 \\
\hline \hline
\end{tabular}

both UPF mode and ZVR mode.

\section{EXPERIMENTAL VALIDATION}

The laboratory setup of the DSTATCOM for experimental evaluation is used. Sensing quantities like point of common coupling (PCC) voltages, grid currents, load currents, and DC bus voltage are needed for the DSP processor (dSPACE-1104) for generating of six gate pulses. The voltage quantities are sensed using LEM made LV25P hall effect sensor and current quantities are sensed by LEM made Hall Effect sensors LA55P. For realizing the proposed algorithm in the dSPACE-1104 a sampling rate of $40 \mu \mathrm{sec}$ is used. The available PWM pulses from the d-SPACE controller are amplified using the isolation circuit before being fed to the SEMIKRON made VSC. The isolation circuit is being made with IC $6 \mathrm{~N} 136$ and TL2N2222 which are opto-coupler and transistor respectively. A DSO of four channel made by Agilent is used for the performance analysis of the system. A power quality analyzer made by fluke is used for analyzing the harmonic distortions in steady state condition.

\section{A. Dynamic Performance of DSTATCOM System}

Analysis of the system with adaptive frequency identifier is shown in Fig. 8. System signals like grid currents, load currents and compensator currents are sensed along with grid voltage $\left(V_{\text {abg }}\right)$ and DC bus voltage $\left(V_{\text {dc }}\right)$ during dynamic load proves the effective operation in UPF mode. Dynamic load condition is created by intermittent load of $50 \Omega$ followed by regular load injection of $21 \Omega$. Fig. 8(a) illustrates the grid, load and compensator currents along with grid voltage. Similarly, Fig. 8 (b) - (d) illustrates the reaction of all phase currents of grid $\left(I_{\text {ag, }}\right.$, $I_{\mathrm{bg}}$, and $\left.I_{\mathrm{cg}}\right)$, load $\left(I_{\mathrm{aL}}, I_{\mathrm{bL}}\right.$, and $\left.I_{\mathrm{cL}}\right)$ and compensator currents $\left(I_{\mathrm{aC}}\right.$, $I_{\mathrm{bC}}$, and $\left.I_{\mathrm{cC}}\right)$ with respect to grid voltage. Fig. 8(e) illustrates the grid, load and compensator currents along with grid voltage DC bus voltage. During transition from dynamic intermittent load injection to regular load injection, the variation in grid current amplitude is observed. Fig. 8(f) shows the zoomed version of Fig. 8(e). The DC bus voltage is recovered in two cycles without crossing the controlled limit which is evident from Fig. 8(f).This matches the simulated results. These observations conclude the dynamic condition of the system is satisfactory.

\section{B. Steady State Performance of DSTATCOM}

An illustration with the waveforms of grid current $\left(i_{\mathrm{ag}}\right)$, load current $\left(i_{\mathrm{aL}}\right)$, and compensator current $\left(i_{\mathrm{aC}}\right)$ along with grid voltage $\left(V_{\text {abg }}\right)$ under steady state is shown in Fig. 9(a)-(c). The harmonic analysis of grid current of phase "a" is shown in Fig. 9(d) and the distortions are under acceptable range. Fig. 9(e) shows the steady state harmonic analysis of the phase "a" load current. Fig. 9(f) shows the steady state harmonic analysis of the phase "a" voltage. It is observed that harmonics of grid current is of $4.7 \%$ and grid voltage is $4.7 \%$. Load harmonics is $23.4 \%$. This elucidates the acceptable function of DSTATCOM in UPF mode of operation. Fig. $9(\mathrm{~g})$ shows active power at the grid as $2.15 \mathrm{~kW}$ and reactive power as $0.13 \mathrm{kVAR}$, Fig. 9(h) shows active power at the load as $2.26 \mathrm{~kW}$ and reactive power as 1.35 kVAR and Fig. 9(i) shows the active power at the compensator as $0.06 \mathrm{~kW}$ and reactive power as $1.19 \mathrm{kVAR}$. The nonlinear load considered here is $\mathrm{AC}$ voltage controller with resistive load.

The amount of active power and reactive power before DSTATCOM compensates it is $2.26 \mathrm{~kW}$ and $1.35 \mathrm{kVAR}$ respectively, which is evident from the power analysis captured at the DSTATCOM. The grid drives the active power to the compensator and load. The compensator drives the reactive power to the load and grid. This is proved by the unity displacement factor at the grid terminals. This verifies the acceptable operation of the system for the considered AC voltage controller type non-linear load.

\section{CONCLUSION}

As an essence in this work a new method of approach is used for fundamental extraction using an adaptive observer. The analysis on the adaptive observer is done using the response of DC bus voltage and AC terminal voltage of system under dynamic load condition and fundamental extraction capability. The considered adaptive observer provides suitable performance for impure load current with phase imbalance in both UPF mode and ZVR mode in MATLAB/Simulink environment. During dynamic conditions, speedy recovery of the system is observed. Harmonic mitigation capabilities can be observed since the adaptive observer based control algorithm lessens the grid current THD $(<5 \%)$ from $21.81 \%$. Even during phase imbalance adaptive observer has mined the fundamental signals with constant amplitude. The proposed adaptive observer has been used to extract the fundamental from load current was evaluated with the SSOA optimized gains in MATLAB and realized by means of d-SPACE. Optimized gains provide a settling time of $0.48 \mathrm{sec}$ and rise time of $0.5 \mathrm{sec}$ during starting and during intermittent load dynamics. The adaptive observer based control algorithm for DSTATCOM provides proper results and it is taking two fundamental cycles for extraction.

\section{Appendix A: Parameters for Simulation Work}

AC mains: 3 phase, $415 \mathrm{~V}$ (line), $50 \mathrm{~Hz}$, source impedance: $R_{\mathrm{s}}=0.06 \Omega, L_{\mathrm{s}}=1 \mathrm{mH}$; non-linear load: AC voltage controller with $R=12 \Omega, L=2 \mathrm{mH}, R=50 \Omega$ and $L=2 \mathrm{mH}$ during unbalance; DC-link voltage: $700 \mathrm{~V}$; sampling time $\left(t_{\mathrm{s}}\right)=10$ $\mu \mathrm{s}$; DC-link capacitor $\left(C_{\mathrm{dc}}\right): 5000 \mu \mathrm{F}$; interfacing inductor $\left(L_{\mathrm{f}}\right)$ 


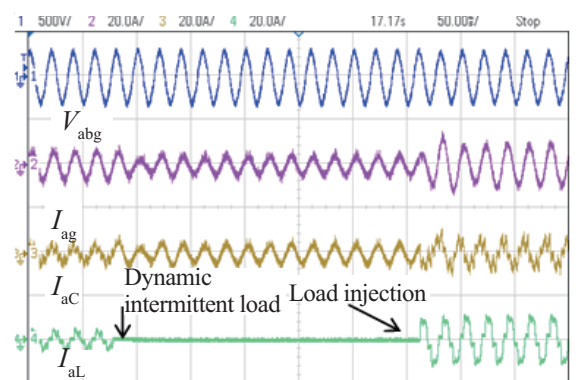

(a)

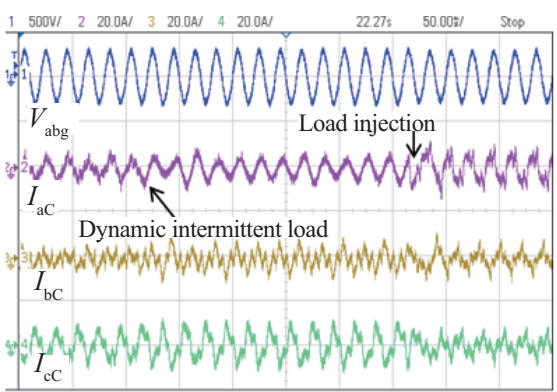

(d)

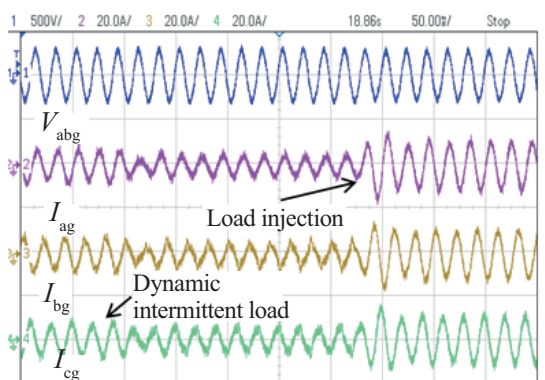

(b)

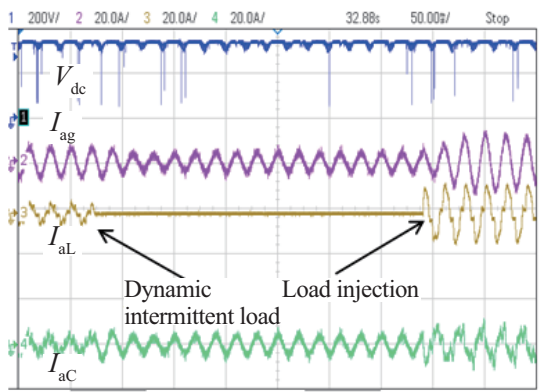

(e)

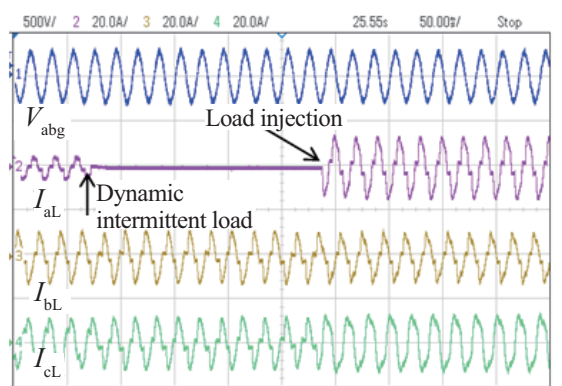

(c)

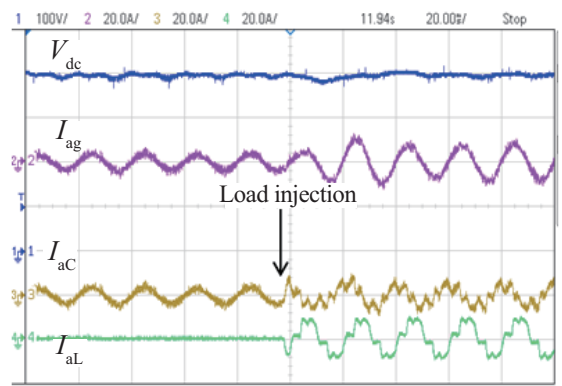

(f)

Fig. 8. System performance with DSTATCOM, (a) $\mathrm{Ch}_{1}: V_{\mathrm{abg}} ; \mathrm{Ch}_{2}: I_{\mathrm{ag}} ; \mathrm{Ch}_{3}: I_{\mathrm{aL}} ; \mathrm{Ch}_{4}: I_{\mathrm{aC}}$, (b) $\mathrm{Ch}_{1}: V_{\mathrm{abg}} ; \mathrm{Ch}_{2}: I_{\mathrm{aG}} ; \mathrm{Ch}_{3}: I_{\mathrm{bG}} ; \mathrm{Ch}_{4}: I_{\mathrm{cg}}$, (c) $\mathrm{Ch}_{1}: V_{\mathrm{abg}} ; \mathrm{Ch}_{2}: I_{\mathrm{aL}} ; \mathrm{Ch}_{3}: I_{\mathrm{bL}} ; \mathrm{Ch}_{4}: I_{\mathrm{cL}},(\mathrm{d})$ $\mathrm{Ch}_{1}: V_{\mathrm{abg}} ; \mathrm{Ch}_{2}: I_{\mathrm{ac}} ; \mathrm{Ch}_{3}: I_{\mathrm{bc}} ; \mathrm{Ch}_{4}: I_{\mathrm{cC}},(\mathrm{e}) \mathrm{Ch}_{1}: V_{\mathrm{dc}} ; \mathrm{Ch}_{2}: I_{\mathrm{ag}} ; \mathrm{Ch}_{3}: I_{\mathrm{ac}} ; \mathrm{Ch}_{4}: I_{\mathrm{Al}}(50 \mathrm{~ms} / \mathrm{div}),(\mathrm{f}) \mathrm{Ch}_{1}: V_{\mathrm{dc}} ; \mathrm{Ch}_{2}: I_{\mathrm{ag}} ; \mathrm{Ch}_{3}: I_{\mathrm{ac}} ; \mathrm{Ch}_{4}: I_{\mathrm{aL}}(20 \mathrm{~ms} / \mathrm{div})$.

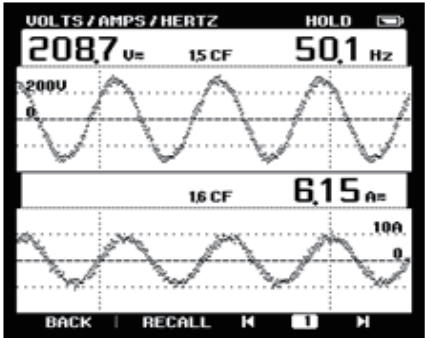

(a)

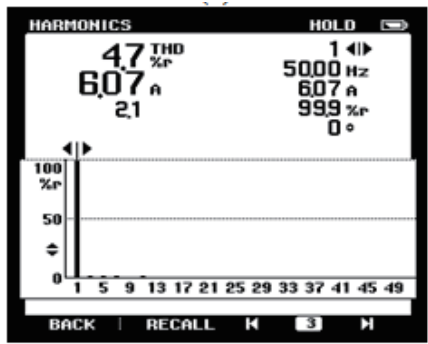

(d)

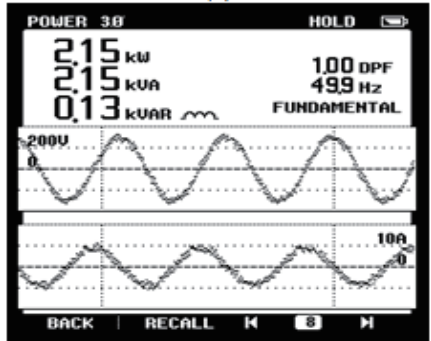

(g)

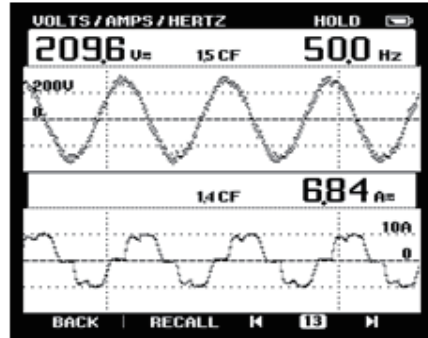

(b)

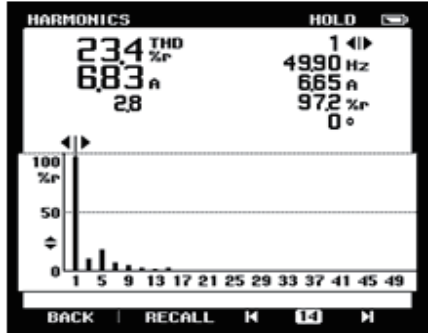

(e)

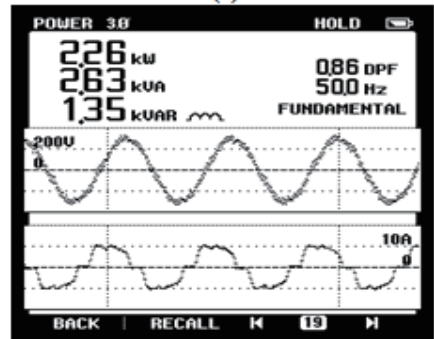

(h)

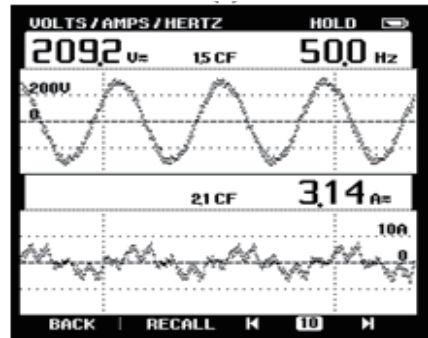

(c)

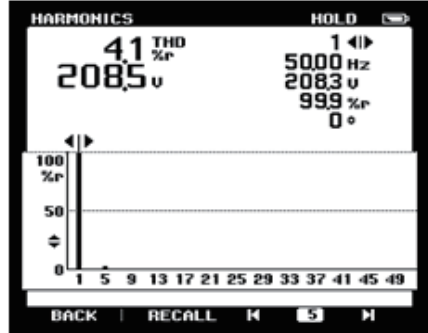

(f)

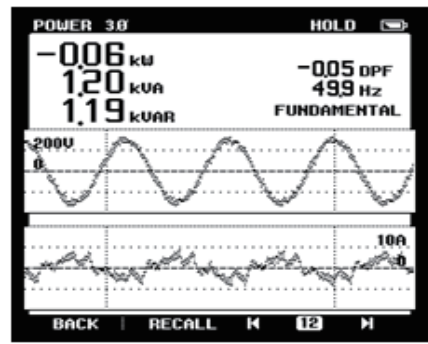

(i)

Fig. 9. Steady state analysis of (a)-(c) $i_{\mathrm{ag}}, i_{\mathrm{aL}}, i_{\mathrm{cC}}$ with respect of $v_{\mathrm{abg}}$. (d)-(f) harmonics spectrum of $i_{\mathrm{ag}}, i_{\mathrm{aL}}, v_{\mathrm{abG}}$. (g)-(i)Active and reactive power analysis for system under study with (g) power supplied by the source, (h) power delivered to load and (i) power at compensator. 
$=2.25 \mathrm{mH}$; switching frequency $\left(f_{\mathrm{s}}\right)=5 \mathrm{kHz}$, DC-link cutoff frequency of LPF: $10 \mathrm{~Hz}$; and AC bus cut-off frequency of LPF: $10 \mathrm{~Hz}$.

\section{APPendix B: PARAMETERS FOR Test Work}

AC mains: 3 phase, $230 \mathrm{~V}$ (line), $50 \mathrm{~Hz}$; non-linear load: AC voltage controller with $R=21 \Omega$ and $R=45 \Omega$ during unbalance; passive filter parameter (ripple filter): $R_{\mathrm{f}}=5 \Omega, C_{\mathrm{f}}$ $=20 \mu \mathrm{F}$; sampling time $\left(T_{\mathrm{s}}\right)=40 \mu \mathrm{s}$, DC-link voltage: $400 \mathrm{~V}$; DC-link capacitor $\left(C_{\mathrm{dc}}\right)=4500 \mu \mathrm{F}$; Interfacing inductor $\left(L_{\mathrm{f}}\right)=$ $4 \mathrm{mH}$; DC-link cut-off frequency of LPF $=10 \mathrm{~Hz}$.

\section{REFERENCES}

[1] A. Moreno Munoz, Power Quality: Mitigation Technologies in a Distributed Environment. U.K.: Springer-Verlag, London, 2007.

[2] M. K. Mishra, A. Ghosh, and A. Joshi, "Operation of a DSTATCOM in voltage control mode," in IEEE Transactions on Power Delivery, vol. 18, no. 1, pp. 258-264, Jan. 2003.

[3] M. Brenna, F. Foiadelli, and D. Zaninelli, "Electromagnetic model of high speed railway lines for power quality studies," in IEEE Transaction on Power Systems, vol. 25, no. 3, pp. 1301-1308, Aug. 2010.

[4] H. L. Jou, J. C. Wu, K. D. Wu, W. J. Chiang, and Y. H. Chen, "Analysis of zig-zag transformer applying in the three-phase four-wire distribution power system," in IEEE Transactions on Power Delivery, vol. 20, no. 2, pp. 1168-1173, Apr. 2005.

[5] R. Cai, M. Bongiorno, and A. Sannino, "Control of D-STATCOM for voltage dip mitigation," in Proceedings of 2005 International Conference on Future Power Systems, Amsterdam, 2005, pp. 1-6.

[6] A. Martins, J. Ferreira, and H. Azevedo, Power Quality. Croatia: Intech Press 2011.

[7] M. S. Reza, M. Ciobotaru, and V. G. Agelidis, "A demodulation based technique for accurate estimation of real-time single-phase grid voltage fundamental parameters," in Proceedings of IECON 2013-39th Annual Conference of the IEEE Industrial Electronics Society, Vienna, Austria, 2013, pp. 6402-6407.

[8] A. Routray, A. K. Pradan, and K. P. Rao, "A novel Kalman filter for frequency estimation of distorted signals in power systems," in IEEE Transactions on Instrumentation and Measurement, vol. 51, no. 3, pp. 469-479, Jun. 2002

[9] R. Weidenbrug, F. P. Dawson, and R. Bonert, "New synchronization method for thyristor power converters to weak AC-systems," in IEEE Transactions on Industrial Electronics, vol. 40, no. 5, Oct. 1993.

[10] Y. Xiaoli, H. Zongshuai, F. Rusen, Y. Heng, X. Haotian, W. Yong, and T. Xiuxia, "Weighted least squares state estimation based on the optimal weight", in Proceedings of 2015 Third International Conference on Technological Advances in Electrical, Electronics and Computer Engineering (TAEECE), Beirut, Lebanon, 2015, pp. 12-16.

[11] B. Singh, J. Solanki, and V. Varma, "Neural netqork based control of reduced rating DSTATCOM, " in Proceedings of annual IEEE India Conference Indicon, 2005, pp. 1830-1841.

[12] Y. Yong, F. Yuaguange, X. Rong, and X. Dianguo, "A method for extracting fundamental-frequency positive-sequence signals based on delayed signal cancellation and low-pass notch filter PLL," in Proceedings of 2014 9th IEEE Conference on Industrial Electronics and Applications, Hangzhou, China, 2014, pp. 1382-1386.

[13] S. Golestan, M. Monfared, F. D. Freijdo, and J. M. Guerrero, “ Dynamics assessment of advanced single phase PLL structures," in IEEE Transactions on Industrial Electronics, vol. 60, no. 6, pp. 2167-2177, Jun. 2013.

[14] Draft Standard for Interconnecting Distributed Resources With Electric Power Systems, IEEE P1547/D08, 2014.

[15] C. H. da Silva, R. R. Pereira, L. E. B. da Silva, G. Lambert-Torres, B. K. Bose, and S. U. Ahn, "A digital PLL scheme for three-phase system using modified synchronous reference frame," in IEEE Transactions on
Industrial Electronics, vol. 57, no. 11, pp. 3814-3821, Nov. 2010.

[16] B. Meersman, J. De Kooning, T. Vandoorn, L. Degroote, B. Renders, and L. Vandevelde, "Overview of PLL methods for distributed generation units," in Proceedings of 45th International University Power Engineering Conference, UPEC2010, Cardiff, UK, Sep. 2010, pp. 1-6.

[17] M. Karimi-Ghartemani, H. Karimi, and M. R. Iravani, "A magnitude/ phase-locked loop system based estimation of frequency and in-phase/ quadrature-phase amplitudes," in IEEE Transactions on Industrial Electronics, vol. 51, no. 2, pp. 511-517, Apr. 2004.

[18] N. Jaalam, N. A. Rahim, A. H. A. Bakar, C. K. Tan, and A. M. A. Haider, "A comprehensive review of synchronization methods for grid-connected converters of renewable energy source," in Renewable and Sustainable Energy Reviews, vol. 59, pp. 1471-1481, Jun. 2016.

[19] M. Popesu, A. Bitoleanu, and C. Vladsuru, "A DSP based implementation of the p-q theory in active power filtering under non ideal voltage conditions," in IEEE Transactions on Industrial Informatics, vol. 9, no. 2, pp. 880-889, May 2013.

[20] L. N. Arruda, B. J. Cardoso Filho, S. M. Silva, S. R. Silva, and A. S. A. C. Diniz, "Wide bandwidth single and three-phase PLL structures for gridtied," in Proceedings of Photovoltaic Specialists Conference, Jan. 2000, pp. $1660-1663$.

[21] A. Carlosena and A. Manuel-Lazaro, "General method for phase-locked loop filter analysis and design," in IET Circuits, Devices \& Systems, vol. 2, no. 2, pp. 249-256, Apr. 2008.

[22] I. Carugati, C. Orallo, P. G. Donato, and S. Maestri, "FPGA design of a variable sampling period PLL with a digital notch filter for distorted grids," in Proceedings of 2011 Argentine School of MicroNanoelectronics, Technology and Applications, Buenos Aires, Argentina, Sep. 2011, pp. 1-6.

[23] Y. F. Wang and Y. W. Li, "A grid fundamental and harmonic component detection method for single phase systems," in IEEE Transactions on Power Electronics, vol.28, no.5, pp. 2204-2213, May. 2013.

[24] X. Xia, "Global frequency estimation using adaptive identifiers," in IEEE Transaction on Automatic Control, vol. 47, no. 7, pp. 1188-1193, Jul. 2002.

[25] Z. Dai, W. Lin, and H. Lin, "Estimation of single-phase grid voltage parameters with zero steady state error," in IEEE Transactions on Power Electronics, vol.31, no.5, pp. 3867-3879, May 2016.

[26] R. T. Marler and J.S. Arora, "Survey of multi objective optimization methods for engineering," in Journal of Structural and Multidisciplinary Optimization, vol. 26, no. 6, pp. 369-395, Mar. 2004.

[27] S. Mirjalili, A. H. Gandomi, S. Z. Mirjalili, S. Saremi, H. Faris, and S. M. Mirjalili, "Salp swarm algorithm: A bio-inspired optimizer for engineering design problems," in Journal of Advances in Engineering Software, vol. 114, no. 2, pp. 163-191, Dec. 2017.

[28] H. Akagi, E. H. Watanabe, and M. Aredes, Instantaneous Power Theory and Applications to Power Conditioning. vol. 31,IEEE Press/Wiley-InterScience, Hoboken, NJ, USA: Wiley, 2007.

[29] M. Gopal, Digital Control and State Variable Methods, Fourth edition. New Delhi: Publishing House of Tata McGraw-Hill, 2012.

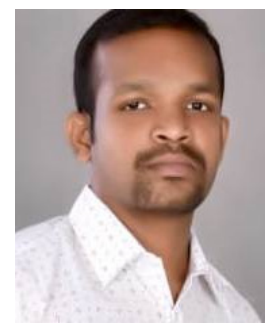

Jayadeep Srikakolapu received the B. Tech.degree (electrical and electronics) from JNTU, Kakinada, India, in 2010 and M.Tech degree in electrical engineering with specialization in power electronics from SGSITS, Indore, India in 2013. In January 2014, he joined the Department of Electrical Engineering, BVC Engineering College, Odalarevu, India, as an Assistant Professor. Currently since January 2018, he is doing Ph.D. programme in Electrical Engineering Department from Sardar Vallabhbhai National Institute of Technology Surat, India. His research interests include power electronics, power quality and design of custom power devices and wind energy conversion systems. 


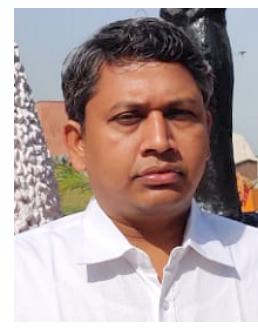

Sabha Raj Arya received B. E. degree in electrical engineering from Government Engineering College Jabalpur, in 2002, M.T. degree in power electronics from Motilal National Institute of Technology, Allahabad, in 2004 and Ph.D. degree in electrical engineering from Indian Institute of Technology (I.I.T) Delhi, New Delhi, India, in 2014. He is joined as Assistant Professor, Department of Electrical Engineering, Sardar Vallabhbhai National Institute of Technology, Surat. January 2019, he is promoted as Associate Professor in same institute. His fields of interest include power electronics, power quality, design of power filters and distributed power generation.

He received two national awards namely INAE Young Engineer Award from Indian National Academy of Engineering, POSOCO Power System Award from Power Grid Corporation of India in the year of 2014 for his research work. He is also received Amit Garg Memorial Research Award-2014 from I.I.T Delhi from the high impact publication in a quality journal during the session 2013-2014. At present, he has published more than hundred research paper in internal national journals and conferences in field of electrical power quality.

He also serves as an Associate Editor for the IET (U.K.) Renewable Power Generation.

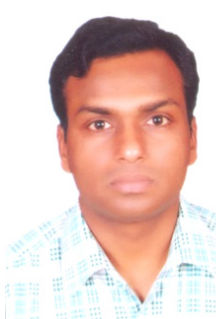

Rakesh Maurya received B. Tech. degree in electrical engineering from the Kamla Nehru Institute of Technology Sultanpur, Uttar Pradesh in 1998 and M. Tech. and Ph.D. degrees in electrical engineering from Indian Institute of Technology Roorkee, India, in 2002 and 2014 respectively. Presently, he is serving as faculty member in the Department of Electrical Engineering, Sardar Vallabhbhai National Institute of Technology Surat, Gujarat, India. His fields of interest include design of switching power converters, high power factor $\mathrm{AC} / \mathrm{DC}$ converters, hybrid output converter, power quality problems, advanced electric drives and applications of real time simulator for the control of power converters. 